\title{
An MRI Brain Atrophy and Lesion Index to Assess the Progression of Structural Changes in Alzheimer's Disease, Mild Cognitive Impairment, and Normal Aging: A Follow-Up Study
}

\author{
Ningnannan Zhang ${ }^{\mathrm{a}, \mathrm{b}}$, Xiaowei Song ${ }^{\mathrm{a}, \mathrm{c}, *}$, Yunting Zhang ${ }^{\mathrm{b}}$, Wei Chen ${ }^{\mathrm{a}, \mathrm{b}}$, Ryan C.N. D'Arcy ${ }^{\mathrm{a}, \mathrm{d}}$, Sultan \\ Darvesh $^{\mathrm{e}, \mathrm{f}}$, John D. Fisk ${ }^{\mathrm{e}, \mathrm{g}}$, Kenneth Rockwood ${ }^{\mathrm{c}, \mathrm{e}, *}$ and Alzheimer's disease Neuroimaging Initiative ${ }^{1}$ \\ ${ }^{a}$ National Research Council Canada Institute for Biodiagnostics (Atlantic), Halifax, NS, Canada \\ ${ }^{\mathrm{b}}$ Department of Radiology of the General Hospital, Tianjin Medical University, Tianjin, China \\ ${ }^{\mathrm{c}}$ Division of Geriatric Medicine, Department of Medicine, Dalhousie University, Halifax, NS, Canada \\ ${ }^{\mathrm{d}}$ Departments of Radiology and Neuroscience, Dalhousie University, Halifax, NS, Canada \\ ${ }^{\mathrm{e}}$ Centre for Health Care of the Elderly, QEII Health Sciences Centre, Halifax, NS, Canada \\ ${ }^{\mathrm{f}}$ Departments of Medicine (Neurology) and Anatomy and Neurobiology, Dalhousie University, Halifax, \\ NS, Canada \\ ${ }^{\mathrm{g}}$ Departments of Psychiatry, Dalhousie University, Halifax, NS, Canada
}

\begin{abstract}
Background: A brain atrophy and lesion index (BALI) based on high-field magnetic resonance imaging (MRI) has recently been validated to evaluate structural changes in the aging brain. The present study investigated the two-year progression of brain structural deficits in people with Alzheimer's disease (AD) and mild cognitive impairment (MCI), and in healthy control older adults (HC) using the BALI rating.
\end{abstract}

\footnotetext{
${ }^{1}$ Data used in preparation of this article were obtained from the Alzheimer's Disease Neuroimaging Initiative (ADNI) database (www.loni.ucla.edu/ADNI). As such, the investigators within the ADNI contributed to the design and implementation of ADNI and/or provided data but did not participate in analysis or writing of this report. ADNI is the result of efforts of many co-investigators from a broad range of academic institutions and private corporations. The Principal Investigator is Michael W. Weiner, MD, VA Medical Center and University of California - San Francisco. ADNI investigators include complete listing available at http://www.loni.ucla.edu/ research/active-investigators.

${ }^{*}$ Correspondence to: Xiaowei Song, PhD, MSCS, National Research Council Canada, Institute for Biodiagnostics (Atlantic), Neuroimaging Research Laboratory, Suite 3900, 1796 Summer Street, Halifax, NS B3H 3A7, Canada. Tel.: +(902) 4731876; Fax: +(902) 4731851; E-mail: Xiaowei.Song@ nrc.ca. Kenneth Rockwood, MD, FRCPC, Divisions of Geriatric Medicine and Neurology, Department of Medicine, Dalhousie University 1421-5955 Veterans Memorial Lane, Halifax, NS, Canada, B3H 2E1. Tel.: +(902) 473 4886; Fax: +(902) 473 1050; E-mail: Kenneth.Rockwood@dal.ca.
} 
Methods: T1-weighted high-resolution anatomical imaging data using 3 Tesla MRI at baseline $(\mathrm{AD}=39, \mathrm{MCI}=82, \mathrm{HC}=58)$ and at 24-months were obtained from the Alzheimer's disease Neuroimaging Initiative database. Lesions in various brain structures, including the infratentorial and basal ganglia areas, and the periventricular and deep white matter and global atrophy, were evaluated and combined into the BALI scale.

Results: Mean progression of brain deficits over two years was evident in all diagnostic groups $(p<0.001)$ and was statistically greater in MCI-AD converters than in the non-converters $(p=0.044)$. An increase in the BALI score was significantly associated with cognitive test scores ( $p=0.008$ for the Mini-Mental State Examination MMSE and $p=0.013$ for the Alzheimer's Disease Assessment Scale-Cognitive Subscale ADAS-cog) in a model that adjusted for age, sex, and education.

Conclusion: The BALI rating quantified the progression of brain deficits over two years, which is associated with cognitive decline. BALI ratings may be used to help summarize AD-associated structural variations.

Keywords: Alzheimer's disease, aging, atrophy, cognition, lesion, visual scale

\section{INTRODUCTION}

Brain structural changes in older adults are commonly revealed on magnetic resonance imaging (MRI) [1] and such changes in otherwise healthy individuals commonly are related to reduced information processing speed and decreased executive capability [2]. Compared with age-associated changes in healthy individuals, brain structural changes in Alzheimer's disease (AD) can involve more profound gray matter atrophy and white matter deficits $[3,4]$. These are often concordant with $\beta$-amyloid accumulation and/or chronic ischemia and small vessel disease, and are related to worse intellectual function $[4,5]$. Reflecting how often more than one pathological disease process is commonly present in older adults, many brain structural changes do not present in isolation, but commonly are associated with each other [6-8].

The importance of considering all types of brain deficits in combination so as to better understand disease expression is increasingly recognized. This requires evaluation of structural changes of the whole brain and their cumulative effect. Even so, the overall impact of multiple brain structural changes on cognition in aging and in AD remains poorly understood, and in this context the evaluation of longitudinal change is paramount. Previous studies have attempted to quantify presumed pathological changes in several localized regions [9] and many have used visual rating scales [3, 10-12] based on T2-weighted imaging or proton density imaging that are sensitive to white matter lesions. More recently, high-field strength MRI (i.e., 3T and higher), using high-resolution T1-weighted imaging has also allowed for visualization of brain abnormities in greater detail $[13,14]$. To capture the range of relevant structural changes, a semi-quantitative brain atrophy and lesion index (BALI) based on high-field MRI has been developed [15]. The BALI approach adapts existing visual rating scales and summarizes various common types of brain structural changes in the aging brain in both supratentorial and infratentorial regions [15]. To date, BALI ratings have been validated using several independent datasets and been found to be useful in describing global structural variability [15]. Even so, it is not yet understood whether this tool can be used to evaluate the progression of brain structural changes and their relation to cognitive decline, a topic of considerable clinical and research interest [16-18].

The objectives of the present study were to investigate the progression of brain structural changes using $\mathrm{BALI}$ in people with $\mathrm{AD}$, people with mild cognitive impairment (MCI), and a matched group of otherwise healthy control subjects (HC), and; to examine the relationship between BALI change and cognitive change. To accomplish these objectives, anatomical imaging data from the Alzheimer's Disease Neuroimaging Initiative were evaluated. A BALI score was constructed for each subject based on T1-weighted MRI at baseline and at 24-months follow-up.

\section{SUBJECTS AND METHODS}

\section{Subjects}

Data used for the present analysis were obtained from the Alzheimer's Disease Neuroimaging Initiative (ADNI) [19]. The ADNI was launched in 2003 by public organizations, private pharmaceutical companies, and non-profit organizations. The primary goal of ADNI has been to test serial neuroimaging and other 
biological markers in the progression of MCI and early $\mathrm{AD}$ in order to aid in more effective treatments [19]. Subjects have been recruited non-randomly from over 50 sites across the U.S.A. and Canada, with a goal of recruiting 800 adults, including 200 cognitively normal older individuals, 400 people with MCI, and 200 people with early AD and to follow them for $2-3$ years [19-21].

Before making them available for public access, all study scans were checked for quality control, so that subjects with structural abnormalities and/or having an image with common scan artifacts were not included in the dataset. The present analysis is restricted to all the data from subjects who had 3T MRI (about $20 \%$ of the total sample) at both baseline and two-year follow-up $(\mathrm{AD}=39 ; \mathrm{MCI}=82 ; \mathrm{HC}=58$ from 30 sites at baseline). At the 24-months follow-up, $13 \mathrm{AD}, 29$ $\mathrm{MCI}$, and $12 \mathrm{HC}$ subjects had dropped out, were lost to follow-up, or had poor quality images. The high resolution (1.2 mm thickness) 3D T1WI using a MP-RAGE sequence were evaluated to generate BALI scores [20]. The quality of all images downloaded from ADNI website was satisfactory and therefore no further selection criteria were imposed for the present analyses.

\section{Imaging evaluation and scoring}

Aging-associated changes in the BALI include ratings of the severity of hypointensities in the infratentorial (IT), deep white matter (DWM), periventricular (PV) and basal ganglia (BG) (Table 1). Ratings were also used to reflect gray matter lesions and the extent

Table 1

Rating schema of the brain atrophy and lesion index

\begin{tabular}{|c|c|c|c|c|c|c|c|}
\hline \multirow[t]{2}{*}{$\overline{\text { Category }}$} & \multirow[t]{2}{*}{ Description } & \multicolumn{6}{|c|}{ Rating } \\
\hline & & 0 & 1 & 2 & 3 & 4 & 5 \\
\hline GM-SV & $\begin{array}{l}\text { lesions in grey } \\
\text { matter and small } \\
\text { vessels }\end{array}$ & absence & $\begin{array}{l}\text { punctuate foci } \\
\text { in grey matter } \\
\text { or multiple } \\
\text { small vessels } \\
\text { in subcortical } \\
\text { areas }\end{array}$ & $\begin{array}{l}\text { beginning of } \\
\text { confluent } \\
\text { foci in grey } \\
\text { matter or } \\
\text { diffuse small } \\
\text { vessels in } \\
\text { subcortical } \\
\text { areas }\end{array}$ & $\begin{array}{l}\text { large confluent } \\
\text { lesions in } \\
\text { grey matter }\end{array}$ & - & - \\
\hline PV & $\begin{array}{l}\text { lesions in } \\
\text { periventricular } \\
\text { regions }\end{array}$ & absence & $\begin{array}{l}\text { "caps" or } \\
\text { pencil-thin } \\
\text { lining }\end{array}$ & smooth "halo" & $\begin{array}{l}\text { periventricular } \\
\text { abnormal } \\
\text { signal } \\
\text { intensities } \\
\text { extending } \\
\text { into the deep } \\
\text { white matter }\end{array}$ & - & - \\
\hline BG & $\begin{array}{l}\text { lesions in basal } \\
\text { ganglia and } \\
\text { surronding areas }\end{array}$ & absence & one focal lesion & $\begin{array}{l}\text { more than one } \\
\text { focal lesions }\end{array}$ & $\begin{array}{l}\text { large confluent } \\
\text { lesions }\end{array}$ & - & - \\
\hline IT & $\begin{array}{l}\text { lesions in } \\
\text { infratentorial } \\
\text { regions }\end{array}$ & absence & one focal lesion & $\begin{array}{l}\text { more than one } \\
\text { focal lesions }\end{array}$ & $\begin{array}{l}\text { large confluent } \\
\text { lesions }\end{array}$ & - & - \\
\hline DWM & $\begin{array}{l}\text { lesions in deep } \\
\text { white matter }\end{array}$ & absence & punctuate foci & $\begin{array}{l}\text { beginning of } \\
\text { confluent } \\
\text { foci }\end{array}$ & $\begin{array}{l}\text { large confluent } \\
\text { areas }\end{array}$ & $\begin{array}{l}\text { large confluent } \\
\text { white matter } \\
\text { areas } \\
\text { involving all } \\
\text { cerebral } \\
\text { lobes }\end{array}$ & $\begin{array}{l}\text { complete } \\
\text { confluent } \\
\text { white matter } \\
\text { disease }\end{array}$ \\
\hline GA & global atrophy & $\begin{array}{c}\text { no atro- } \\
\text { phy }\end{array}$ & mild atrophy & $\begin{array}{l}\text { moderate } \\
\text { atrophy }\end{array}$ & severe atrophy & $\begin{array}{l}\text { most severe } \\
\text { atrophy } \\
\text { presetned } \\
\text { especially in } \\
\text { the medial } \\
\text { temporal } \\
\text { lobes }\end{array}$ & $\begin{array}{l}\text { most severe } \\
\text { atrophy } \\
\text { presented in } \\
\text { the medial } \\
\text { temporal } \\
\text { and cerebral } \\
\text { cortex }\end{array}$ \\
\hline $\begin{array}{l}\text { other } \\
\text { lesions }\end{array}$ & $\begin{array}{l}\text { neoplasm, trauma, } \\
\text { deformation }\end{array}$ & nothing & any one kind & any two kinds & $\begin{array}{l}\text { more than two } \\
\text { kinds }\end{array}$ & - & - \\
\hline
\end{tabular}


of dilatation of small vessels (i.e., small and wellmargined symmetric hypointensities; GM-SV) and global atrophy (GA). An "other lesions" category was included to allow for ratings of neoplasm, trauma, and deformity. The grading scheme followed the BALI construction [15] to adapt existing rating scores that address localized structural changes [3, 10-12] (Table 1). Specifically, a scale was assigned for each category based on the severity of deficits, with higher scores indicating greater severity (Fig. 1). To the existing DWM rating, scores of " 4 " and " 5 " were added, to describe large confluent WM areas involving all cerebral lobes and complete confluent lesions. Similarly, two more levels (i.e., 4 and 5) were included to evaluate progression of global atrophy, where " 4 " indicated most severe atrophy present, especially in the medial temporal lobes, and " 5 " indicated the most severe atrophy present in the medial temporal and cerebral cortex (Table 1).

At each time point, the scans were reviewed separately and the total BALI scores were calculated by summarizing the ratings of all seven categories. Ratings were completed independently by two trained radiologists. Baseline and follow-up images were rated in random order, with the raters blind to demographic data, diagnosis, scan time, and cognitive test results. Inter-rater correlation coefficients (ICC) for BALI total scores were evaluated on a randomly selected sample of $20 \%$ of subjects in each diagnostic group at both baseline and follow-up.

\section{Clinical tests}

Clinical tests and ratings of cognitive functioning at both baseline and follow-up were obtained from the ADNI clinical dataset. These included the Clinical Dementia Rating scale (CDR) and scores on the Mini-Mental State Examination (MMSE) and the Alzheimer's Disease Assessment Scale - cognitive subscale (ADAS-cog). The ADNI protocol required two initial visits. The first was a screening visit (at which time MMSE and CDR testing were performed), followed by a baseline visit (at which time the ADAS$\operatorname{cog}$ and other clinical tests were performed). The 3T MRI scans were to be performed within 42 days after the screening visit and within 14 days of the baseline visit. The follow-up scans were designed to be completed within 14 days of the 24 months follow-up visit (at which time clinical tests including the ADAS-cog, MMSE, and CDR were performed) [21]. For this study sample, the baseline MMSE and CDR were completed on average $40.2 \pm 19.2$ days ahead of the 3T MRI scans, while the ADAS-cog was completed 5.6 \pm 10.7 days ahead of the MRIs. Follow-up cognitive testing was conducted on average $2.6 \pm 10.3$ days ahead of the MRI scans.

Diagnostic categorization of the subjects and classification of conversion between diagnostic groups were both made by the ADNI site physicians in accordance with the criteria of the National Institute of Neurologic and Communicative Disorders and Stroke/Alzheimer's Disease and Related Disorders Association (NINCDS/ADRDA), and were reviewed by ADNI clinical monitors [21]. Analyses involving follow-up data have taken into account information about disease conversion for diagnostic categorization.

\section{Statistical analyses}

Demographic characteristics across diagnostic group were examined using Kruskal-Wallis nonparametric tests for interval data and Chi-Square tests for ordinal data. A general linear model of repeated measures with unbalanced design was used to test the differences in the BALI total score and the cognitive testing scores, with time as within-subject factor and diagnostic-categorization as the between subject factor. All multivariate analyses were adjusted for age, sex, and education level. The main effects of time and diagnosis and their interactions were tested. Relationships between BALI scores at baseline and at follow-up were tested using correlation analyses. The effect of the BALI on cognitive testing scales was evaluated using multivariate linear regression analysis, adjusted for age, sex, education level. Similarly, multivariate linear regression analysis was used to examine the association between the change scores (i. e., followup - baseline) of the BALI and the cognitive tests. All analyses were performed using SPSS $^{\odot} 15.0$ software package and codes developed using Matlab ${ }^{\circledR}$ R2007. Significance level was set at $p<0.05$.

\section{RESULTS}

In general, demographic characteristics were similar across diagnostic groups. Subjects with MCI were more likely to be men ( $p=0.002$; Table 2$)$, otherwise there were no statistical differences in age $(p=0.37)$ or in education $(p=0.84)$, although subjects in the MCI group appeared to be slightly younger, especially the non-converters (Table 2). As expected, a significant difference in cognitive ratings and performance 


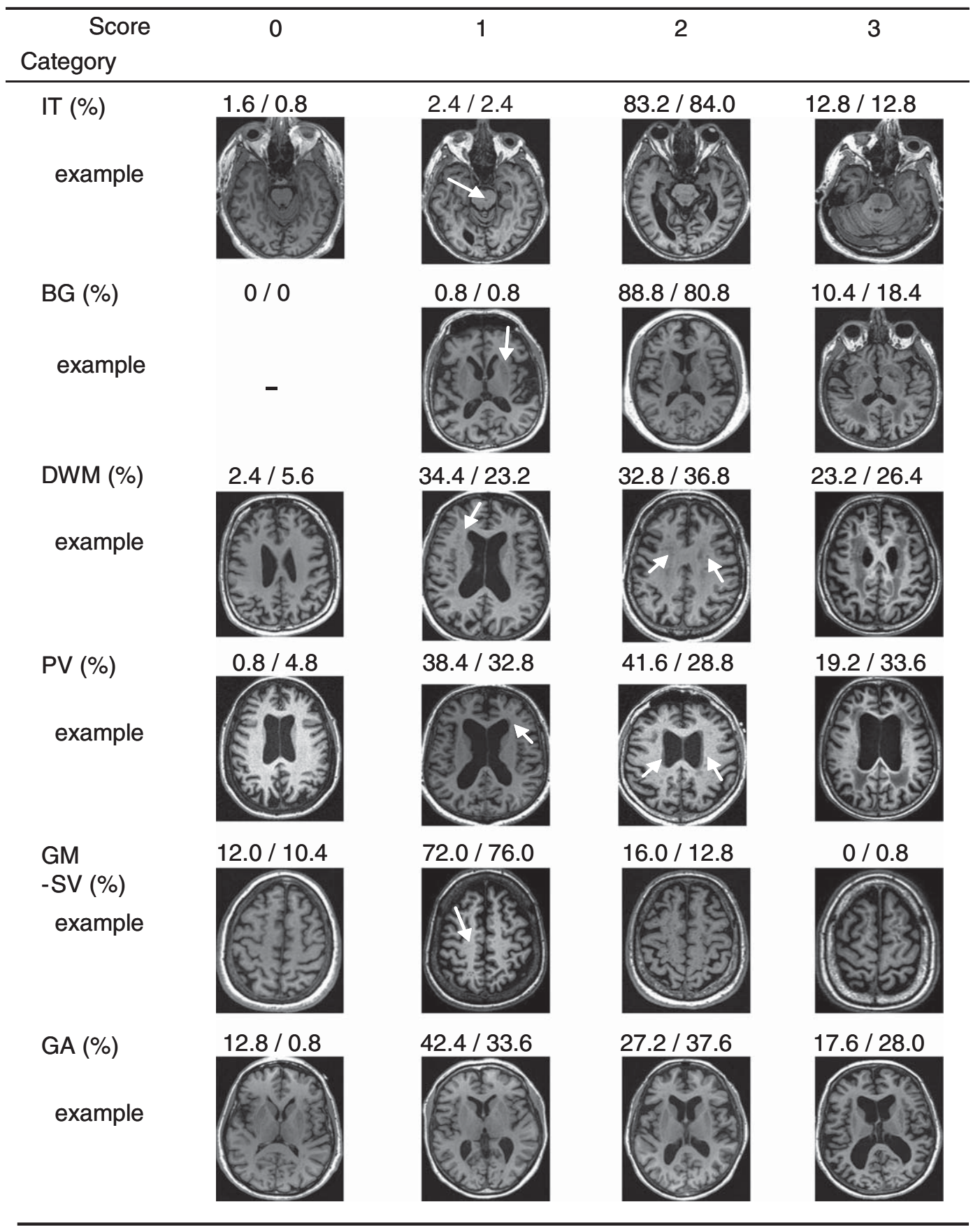

Fig. 1. Example images showing subscore ratings for each category. White arrows indicate where the deficits are located. Percentage of subjects having each score at baseline and at two-year follow-up were given (i.e., baseline/follow-up).

was evident at baseline and at follow-up among the diagnostic groups even when adjusted for age, sex, and education level. $(\mathrm{F}=99.1$ for MMSE, $\mathrm{F}=92.1$ for ADAS-cog; $\left.p_{\mathrm{s}}<0.001\right)$. There was no significant time by diagnosis interaction associated with the two-year decline $(p>0.05)$, despite the noted differences in the timing of administration of the ADAS-Cog and MMSE in relation to the MRI. Note that in this subsample of 
Table 2

Characteristics of the subjects in different diagnostic groups

\begin{tabular}{|c|c|c|c|c|c|c|}
\hline \multirow[t]{2}{*}{ Group } & & \multirow[t]{2}{*}{ Alzheimer's disease } & \multicolumn{2}{|c|}{ Mild cognitive impairment } & \multirow[t]{2}{*}{ Health control } & \multirow[t]{2}{*}{$p^{*}$} \\
\hline & & & Conversion & Stable & & \\
\hline \multirow[t]{2}{*}{ Sample size } & baseline & 39 & & & 58 & \\
\hline & follow-up & 26 & 31 & 22 & 46 & \\
\hline Female (\%) & baseline & 59.0 & 29.0 & 40.9 & 62.1 & 0.002 \\
\hline $\begin{array}{l}\text { Education } \\
\text { (years) }\end{array}$ & baseline & $14.7 \pm 2.4$ & $15.7 \pm 2.7$ & $14.9 \pm 2.8$ & $15.4 \pm 2.7$ & 0.844 \\
\hline Age (years) & baseline & $75.7 \pm 9.4$ & $74.2 \pm 8.2$ & $72.9 \pm 7.0$ & $76.0 \pm 5.1$ & 0.369 \\
\hline \multirow[t]{2}{*}{ MMSE (/30) } & baseline & $23.0 \pm 2.1$ & $26.4 \pm 1.8$ & $27.6 \pm 2.0$ & $29.3 \pm 0.9$ & 0.001 \\
\hline & follow-up & $18.3 \pm 6.1$ & $22.8 \pm 3.6$ & $27.9 \pm 2.6$ & $29.1 \pm 1.1$ & $<0.001$ \\
\hline \multirow{2}{*}{$\begin{array}{l}\text { ADAS-cog } \\
(/ 70)\end{array}$} & baseline & $18.6 \pm 6.8$ & $13.8 \pm 3.4$ & $9.1 \pm 4.0$ & $5.3 \pm 2.5$ & $<0.001$ \\
\hline & follow-up & $27.8 \pm 12.7$ & $17.0 \pm 6.5$ & $10.2 \pm 4.6$ & $5.6 \pm 2.7$ & $<0.001$ \\
\hline \multirow[t]{2}{*}{${ }^{\#}$ CDR (0-3) } & baseline & $0.7 \pm 0.2(0.5)$ & $0.5 \pm 0.0(0.5)$ & $0.5 \pm 0.0(0.5)$ & $0(0)$ & $<0.001$ \\
\hline & follow-up & $1.2 \pm 0.6(1)$ & $0.8 \pm 0.3$ & $0.5 \pm 0.1(0.5)$ & $0 \pm 0.1(0)$ & $<0.001$ \\
\hline \multirow[t]{2}{*}{ BALI (/25) } & baseline & $11.2 \pm 3.1$ & $10.7 \pm 2.8$ & $9.5 \pm 2.6$ & $9.9 \pm 2.4$ & 0.072 \\
\hline & follow-up & $12.4 \pm 2.7$ & $12.0 \pm 2.7$ & $9.9 \pm 2.1$ & $11.0 \pm 2.4$ & 0.001 \\
\hline
\end{tabular}

Note: Data are presented as mean \pm standard deviate, otherwise as indicated. AD: Alzheimer's disease. MCI: Mild Cognitive Impairment. HC: healthy control subjects. MMSE: Mini-Mental Status Examination. ADAS-cog: Alzheimer's Disease Assessment Scale-cognitive subscale. CDR: Clinical Dementia Rating. BALI: Brain Atrophy and Lesion Index. $\mathrm{p}^{*}$ : Diagnostic group differences were examined using uni-variate Kruskal-Wallis nonparametric tests for interval data and Chi-Square tests for ordinal data. For the baseline comparisons, means of the AD, pooled MCI, and HC groups were compared. For the follow-up data, means of the pooled AD and converter MCI, non-converter MCI, and HC groups were compared. \# Median value is presented in brackets.

people with $3 \mathrm{~T}$ scans, none of the $\mathrm{AD}$ patients were re-classified as having MCI; likewise, only one of the healthy controls progressed to a diagnosis of MCI. Within the MCI group, most (31/53) had progressed to a diagnosis of AD by follow-up (Table 2).

The overall inter-rater agreement rate for BALI ratings was high (ICC $=90.8 \%$ ). Brain structural deficits were common in all groups (Table 2) and on average increased (showed worsening) in each diagnostic group. This worsening of scores over time, with significant differences between diagnostic groups persisted when the analyses were adjusted for age, sex, and education $\left(\mathrm{F}_{\text {time }}=49.1, \quad p<0.001 ; \mathrm{F}_{\text {diagnosis }}=3.62\right.$, $p=0.030$ ) but without a significant time-diagnosis interaction. Note that whereas subjects with $A D$ and MCI-AD converters showed the highest BALI values, the mean difference in BALI between the nonconverters and health controls was not statistically significant $(p>0.05)$. Overall, the MCI-AD converter group showed a greater increase in the BALI (i.e., more brain structural deficits) than did MCI non-converters. The BALI scores at baseline and follow-up were highly correlated $\left(r^{2}=0.78, p<0.01\right)$, although a few MCI non-converters and $\mathrm{HC}$ subjects showed a decrease in BALI over the two-year period. The maximum BALI score at baseline was 16 ( 0.64 of the total score) and 18 (0.72) at follow-up, showing no ceiling effect, despite average disease progression.

Given mean worsening in both structure (BALI scores) and function (MMSE, ADAS-Cog) the relationship between the two is of interest. The BALI score was significantly related both to MMSE at baseline (regression coefficient $\mathrm{B}=-0.310 ; t=-2.71 ; p=$ $0.008)$ and at follow-up $(\mathrm{B}=-0.725 ; t=-3.5$; $p=0.001)$ and to ADAS-cog at baseline $(\mathrm{B}=0.612 ; t=$ $2.521 ; p=0.013)$ and at follow-up $(\mathrm{B}=1.26 ; t=3.02$; $p=0.003$ ), in a multivariable linear regression adjusted for age, sex and education. The change in BALI between baseline and follow-up was also associated with the change in MMSE (i.e., $\triangle \mathrm{MMSE}$; $\mathrm{B}=-0.226$; $t=-2.176 ; p=0.031$ ). By contrast, change in the BALI was not significantly associated with the change in the ADAS-cog $(p=0.25)$. Of the $30 \mathrm{MCI}$ subjects who showed a worsening in MMSE (i.e., $\left.\operatorname{MMSE}_{\text {(follow-up-baseline) }}<0\right), 25(83 \%)$ also showed a worsening in BALI (i.e., BALI $\mathrm{I}_{\text {follow-up-baseline }}>0$ ); the BALI scores of the remaining 5 people did not change. Similarly, of the 23 MCI people who showed a stable or improved MMSE, $15(66 \%)$ had a stable or improved $\operatorname{BALI}\left(X^{2}=14.2, p=0.007\right)$. 


\section{DISCUSSION}

In this secondary analysis of 3T MRI data, several common types of brain structural changes in $\mathrm{AD}$, MCI and healthy controls could be quantified in a Brain Atrophy and Lesion Index (BALI) score, to evaluate overall brain deficits and their relationship to cognitive function. Over two years, people in each diagnostic group, on average, experienced increasing atrophy and more structural brain lesions. Cognitive test scores worsened in the AD group, and in most people with MCI, but were relatively stable in healthy controls and in a minority with MCI. In AD and in the people with MCI who by two years had progressed to $\mathrm{AD}$, structural brain changes as indicated by the BALI score, and brain function as measured by the MMSE deteriorated in parallel. The accumulation of brain structural deficits in association with cognitive decline corresponds to lessons from large prospective neuropathological studies [6,7] and supports the use of BALI to quantify whole brain changes in AD, MCI and normal aging [15].

It is of clear clinical and public health significance to understand the relationships between structural brain changes and changes in cognitive functioning as they occur in the development of $\mathrm{AD}$, recognizing that $\mathrm{AD}$ involves multiple brain changes, including atrophy, white matter lesions, and vascular changes $[8,22]$. Methods of collectively studying the cumulative impact of these many structural deficits have been sought $[6,7]$ and BALI ratings appear to fill this need. In particular, the BALI rating is easily accessible because it can be based on T1-weighted high-resolution imaging, the most routinely acquired sequence in MRI investigations. While many studies seek to establish the relationship between specific cognitive abilities and specific types of brain deficits, most cognitive tasks require the integrated functioning of a variety of neural networks. BALI ratings can serve to describe global structural status in a manner that allows for global cognitive dysfunction to be related to the accumulation of brain structural deficits.

Here, people with AD and those with MCI who progressed to AD showed both cognitive and structural decline. The BALI allows us to demonstrate the association between brain structural changes and cognitive decline using a cumulative index. Similar findings have been reported in earlier studies that were typically based on individual structural measures [18]. For example, recent serial MRI studies have suggested hippocampal atrophy or ventricular enlargement is predic- tive of cognitive decline and/or AD conversion $[9,16$, $17,23]$. The rate of change of white matter damage has also been used to predict cognitive decline [18, 27]. It is also worth noting that while most people in the study sample had stable or greater brain deficits over two years, a small number of stable MCI and HC subjects did have a decreased BALI. Whereas, most people with brain structural worsening also had cognitive worsening, some did show improved cognitive test scores, possibly in keeping with the concept of cognitive reserve [28]. Importantly however, of those who converted to $\mathrm{AD}$, none showed an improvement in BALI.

Our data must be interpreted with caution. Rating scales have inherently low precision with respect to volumetric measurements. For example, voxel/ volume-base morphography can often reveal quantitative atrophy changes of about $1 \%$ per year [9], whereas with BALI a minimum increment of any domain including atrophy is one point. In other words, assigning a precise value using a rating scale may not be as easy as visualizing an apparent deficit. Even so, in practice, valid visual rating scales are particularly beneficial and welcome in clinical settings when evaluation time is a concern [29]. The scoring system utilized in this study has been adapted from existing rating scales and been validated by previous research [15]. Furthermore, the relatively high inter-rater reliability suggests that the BALI ratings can be consistently performed by different raters with training of the method.

To now construction of the BALI has not considered the assignment of relative weights to different BALI components, even though these clearly can affect cognition differently (e.g. medial temporal atrophy [30]). The algorithms for determining appropriate weights for BALI components are yet to be established. There may in fact be inherent benefit to a scale without weights, as weights for individual BALI items may vary across datasets, targeted outcome measures, follow-up durations, and study focus. In short, while weighting might improve prediction in a given dataset, it can impair generalizability. This needs to be evaluated.

Several other caveats also apply to our study; among these the fact that cognitive evaluations were limited to the MMSE, ADAS-cog, and CDR. Both MMSE and ADAS-cog can have ceiling effects with $\mathrm{HC}$ and MCI subjects that make sensitivity to change an issue for longitudinal studies. The number of people in whom the CDR increased (indicating worsening cognition and function) and/or converted to AD over two years was also relatively low, further limiting the sensitivity 
to detect the association between cognitive decline and brain deficit progression. Here, in the subjects limited to those with $3 \mathrm{~T}$ data, only one healthy control progressed to MCI or AD. In addition, while the time difference between MRI scans and the cognitive assessments were within a few days for all of the follow-up tests and for the baseline ADAS-cog, baseline MMSE and CDR were completed approximately 40 days in advance of the baseline imaging acquisition. Clearly it would have been preferable to have baseline clinical testing that was closer in time to the initial MRI scan. Lastly, we lack the knowledge of treatment effects in the AD and MCI groups, and therefore cannot identify whether any improvement in cognition and/or brain structure was related to treatment. Despite these limitations, the overall brain deficits as measured by BALI were related to the global cognitive assessment scales used in this study, at both baseline and follow-up. In the future, large-scale serial MRI research involving multiple follow-ups over longer terms and more detailed clinical assessments would be particularly valuable. Better understanding the relationships between structural and functional changes can help improve clinical management and preclinical strategies for $\mathrm{AD}$ [31].

In summary, the present study suggests that significant brain changes and cognitive changes can occur within two years in people with MCI and AD and in otherwise healthy elderly people. The BALI provides a readily available means to evaluate brain structural changes and their relation to cognitive decline as well as conversion to $\mathrm{AD}$ from MCI.

\section{ACKNOWLEDGMENTS}

This research was supported by the Nova Scotia Research Foundation (NSHRF-MED2086), the Capital Health Research Foundation (CDHA-RO33), the National Basic Research Program of China (973 Program, \# 2010CB732500), and National Natural Science Foundation of China (Major Program, \# 30730036). NZ receives an NRC fellowship from the Chinese Ministry of Education and a research grant from the Postgraduate Foundation of Tianjin Medical University (\# 2009GSI13) as a joint PhD candidate. KR receives career support from the Dalhousie Medical Research Foundation as the Kathryn Allen Weldon Professor of Alzheimer Research.

We acknowledge Drs. Sandra Black, Robert Vandorpe, Steven Beyea, Chris Bowen for valuable discussions, Denise Lalanne and Elizabeth Vandermolen for proof-reading of the manuscript.

Data collection and sharing for this project was funded by the Alzheimer's Disease Neuroimaging Initiative (ADNI) (National Institutes of Health Grant U01 AG024904). ADNI is funded by the National Institute on Aging, the National Institute of Biomedical Imaging and Bioengineering, and through generous contributions from the following: Abbott, AstraZeneca AB, Bayer Schering Pharma AG, BristolMyers Squibb, Eisai Global Clinical Development, Elan Corporation, Genentech, GE Healthcare, Glaxo SmithKline, Innogenetics, Johnson and Johnson, Eli Lilly and Co., Medpace, Inc., Merck and Co., Inc., Novartis AG, Pfizer Inc, F. Hoffman-La Roche, Schering-Plough, Synarc, Inc., and Wyeth, as well as non-profit partners the Alzheimer's Association and Alzheimer's Drug Discovery Foundation, with participation from the U.S. Food and Drug Administration. Private sector contributions to ADNI are facilitated by the Foundation for the National Institutes of Health (www.fnih.org <http://www.fnih.org > [SELFCLOSE] $</$ http://www.fnih.org $>$ ). The grantee organization is the Northern California Institute for Research and Education, and the study is coordinated by the Alzheimer's Disease Cooperative Study at the University of California, San Diego. ADNI data are disseminated by the Laboratory for Neuro Imaging at the University of California, Los Angeles. This research was also supported by NIH grants P30 AG0 10129, K01 AG030514, and the Dana Foundation.

\section{REFERENCES}

[1] Drayer BP (1988) Imaging of the aging brain. Part I. Normal findings. Radiology 166, 785-796.

[2] Brickman AM, Zimmerman ME, Paul RH, Grieve SM, Tate DF, Cohen RA, Williams LM, Clark CR, Gordon E (2006) Regional white matter and neuropsychological functioning across the adult lifespan. Biological Psychiatry 60, 444-453.

[3] Duara R, Loewenstein DA, Potter E, Appel J, Greig MT, Urs R, Shen Q, Raj A, Small B, Barker W, Schofield E, Wu Y, Potter H (2008) Medial temporal lobe atrophy on MRI scans and the diagnosis of Alzheimer disease. Neurology 71, 19861992.

[4] Brickman AM, Muraskin J, Zimmerman ME (2009) Structural neuroimaging in Alzhmeimer's disease: do white matter hyperintensities matter? Dialogues Clin Neurosci 11, 181190.

[5] Black S, Gao F, Bilbao J (2009) Understanding white matter disease: imaging-pathological correlations in vascular cognitive impairment. Stroke 40, S48-S52.

[6] Savva GM, Wharton SB, Ince PG, Forster G, Matthews FE, Brayne C, Medical Research Council Cognitive Function, 
Ageing, Study (2009) Age, neuropathology, and dementia. N Engl J Med 360, 2302-2309.

[7] White L (2009) Brain lesions at autopsy in older JapaneseAmerican men as related to cognitive impairment and dementia in the final years of life: a summary report from the Honolulu-Asia aging study. J Alzheimers Dis 18, 713-725.

[8] Capizzano AA, Acion L, Bekinschtein T, Furman M, Gomila H, Martínez A, Mizrahi R, Starkstein SE (2004) White matter hyperintensities are significantly associated with cortical atrophy in Alzheimer's disease. J Neurol Neurosurg Psychiatry 75, 822-827.

[9] Jack CR Jr, Shiung MM, Gunter JL, O'Brien PC, Weigand SD, Knopman DS, Boeve BF, Ivnik RJ, Smith GE, Cha RH, Tangalos EG, Petersen RC (2004) Comparison of different MRI brain atrophy rate measures with clinical disease progression in AD. Neurology 62, 591-600.

[10] Kapeller P, Barber R, Vermeulen J, Adèr H, Scheltens P, Freidl W, Almkvist O, Moretti M, del Ser T, Vaghfeldt P, Enzinger C, Barkhof F, Inzitari D, Erkinjunti T, Schmidt R, Fazekas F (2003) European Task Force of Age Related White Matter Changes, Visual rating of age-related white matter changes on magnetic resonance imaging: scale comparison, interrater agreement, and correlations with quantitative measurements. Stroke 34, 441-445.

[11] Wahlund LO, Barkhof F, Fazekas F, Bronge L, Augustin M, Sjögren M, Wallin A, Ader H, Leys D, Pantoni L, Pasquier F, Erkinjuntti T, Scheltens P (2001) European Task Force on Age-Related White Matter Changes, A new rating scale for age-related white matter changes applicable to MRI and CT Stroke 32, 1318-1322.

[12] Scheltens P, Barkhof F, Leys D, Pruvo JP, Nauta JJ, Vermersch P, Steinling M, Valk J (1993) A semiquantative rating scale for the assessment of signal hyperintensities on magnetic resonance imaging. J Neurol Sci 114, 7-12.

[13] Alvarez-Linera J (2008) 3T MRI: advances in brain imaging. Eur J Radiol 67, 415-426.

[14] Duyn JH (2010) Study of brain anatomy with high-field MRI: recent progress. Magn Reson Imaging 28, 1210-1215.

[15] Chen W, Song X, Zhang Y, Darvesh S, Zhang N, D' Arcy RC, Black S, Rockwood K (2010) An MRI-based semiquantitative index for the evaluation of brain atrophy and lesions in Alzheimer's disease, mild cognitive impairment and normal aging. Dement Geriatr Cogn Disord 30, 121-130.

[16] den Heijer T, van der Lijn F, Koudstaal PJ, Hofman A, van der Lugt A, Krestin GP, Niessen WJ, Breteler MM (2010) A 10-year follow-up of hippocampal volume on magnetic resonance imaging in early dementia and cognitive decline. Brain 133, 1163-1172.

[17] Whitwell JL, Przybelski SA, Weigand SD, Knopman DS, Boeve BF, Petersen RC, Jack CR Jr (2007) 3D maps from multiple MRI illustrate changing atrophy patterns as subjects progress from mild cognitive impairment to Alzheimer's disease. Brain 130, 1777-1786.

[18] Silbert LC, Howieson DB, Dodge H, Kaye JA (2009) Cognitive impairment risk: white matter hyperintensity progression matters. Neurology 73, 120-125.

[19] Werner MW, Aisen PS, Jack CR Jr, Jagust WJ, Trojanowski JQ, Shaw L, Saykin AJ, Morris JC, Cairns N, Beckett LA, Toga A, Green R, Walter S, Soares H, Snyder P, Siemers E, Potter W, Cole PE, Schmidt M (2010) Alzheimer's Disease Neuroimaging Initiative, The Alzheimer's disease neuroimaging initiative: progress report and future plans. Alzheimer's Dement 6, 201-211.

[20] Jack CR Jr, Bernstein MA, Fox NC, Thompson P, Alexander G, Harvey D, Borowski B, Britson PJ, Whitwell JL, Ward C, Dale AM, Felmlee JP, Gunter JL, Hill DL, Killiany R, Schuff N, Fox-Bosetti S, Lin C, Studholme C, DeCarli CS, Krueger G, Ward HA, Metzger GJ, Scott KT, Mallozzi R, Blezek D, Levy J, Debbins JP, Fleisher AS, Albert M, Green R, Bartzokis G, Glover G, Mugler J, Weiner MW (2008) The Alzheimer's Disease Neuroimaging Initiative (ADNI): MRI methods. J Magn Reson Imaging 27, 685-691.

[21] ADNI General Procedures Manual, http://www.loni.ucla.edu/ research/protocols/clinical-protocols/ADNI General Procedures Manual.pdf.

[22] van der Flier WM, Middelkoop HA, Weverling-Rijnsburger AW, Admiraal-Behloul F, Spilt A, Bollen EL, Westendorp RG, van Buchem MA (2004) Interaction of medial temporal lobe atrophy and white matter hyperintensities in AD. Neurology 62, 1862-1864.

[23] Sean MN, Raul R, Michael B, Smith M, Accomazzi V, Wells JL, Fogarty J, Bartha R (2008) Alzheimer's Disease Neuroimaging Initiative, Ventricular enlargement as a possible measure of Alzheimer's disease progression validated using the Alzheimer's disease neuroimaging initiative database. Brain 131, 2443-2454.

[24] Driscoll I, Davatzikos C, An Y, Wu X, Shen D, Kraut M, Resnick SM (2009) Longitudinal pattern of regional brain volume change differentiates normal aging from MCI. Neurology 72, 1906-1913.

[25] Ezekiel F, Chao L, Kornak J, Du AT, Cardenas V, Truran D, Jagust W, Chui H, Miller B, Yaffe K, Schuff N, Weiner M (2004) Comparisons between global and focal brain atrophy rates in normal aging and Alzheimer disease: Boundary Shift Integral versus tracing of the entorhinal cortex and hippocampus. Alzheimer Dis Assoc Disord 18, 196-201.

[26] DeCarli C, Fletcher E, Ramey V, Harvey D, Jagust WJ (2005) Anatomical Mapping of White Matter Hyperintensities (WMH). Exploring the relationships between periventricular WMH, deep WMH, and total WMH burden. Stroke 36, 50-55.

[27] Brickman AM, Honig LS, Scarmeas N, Tatarina O, Sanders L, Albert MS, Brandt J, Blacker D, Stern Y (2008) Measuring cerebral atrophy and white matter hyperintensity burden to predict the rate of cognitive decline in Alzheimer disease. Archives of neurology 65, 1202-208.

[28] Stern Y (2009) Cognitive reserve. Neuropsychologia 47, 2015-2028.

[29] Gouw AA, van der Flier WM, van Straaten EC, Pantoni L, Bastos-Leite AJ, Inzitari D, Erkinjuntti T, Wahlund LO, Ryberg C, Schmidt R, Fazekas F, Scheltens P, Barkhof F; LADIS study group (2008) Reliability and sensitivity of visual scales versus volumetry for evaluating white matter hyperintensity progression. Cerebrovasc Dis 25, 247-253.

[30] Enzinger C, Fazekas F, Matthews PM, Ropele S, Schmidt H, Smith S, Schmidt R (2005) Risk factors for progression of brain atrophy in aging: six-year follow-up of normal subjects. Neurology 24, 1704-1711.

[31] Frisoni GB, Fox NC, Jack CR Jr, Scheltens P, Thompson PM (2010) The clinical use of structural MRI in Alzheimer disease. Nat Rev Neurol 6, 67-77. 